\title{
A Comparative Analysis of Center for Independent Living Staff and Board of Directors Regarding CIL Services and Consumer Participation
}

\author{
Craig Ravesloot, $\mathrm{PhD}$ \\ Research and Training Center on Disability in Rural Communities \\ University of Montana \\ Glen W. White, PhD \\ Research and Training Center on Independent Living \\ University of Kansas \\ Chiaki Gonda-Kotani, MA \\ Ritsumeikan University, Graduate School of Ethics and Frontier Sciences \\ Kelsey Shinnick, BA \\ Research and Training Center on Independent Living \\ University of Kansas
}

\begin{abstract}
Author Note
The research reported here was supported by the National Institute of Disability and Rehabilitation Research, U.S. Department of Education, through Grant No. H133B11006 to the University of Kansas. The opinions expressed are those of the authors and do not represent views of the National Institute of Disability and Rehabilitation Research or the U.S. Department of Education. Correspondence concerning this article should be addressed to Craig Ravesloot, Ph.D., Research and Training Center on Disability in Rural Communities, University of Montana, Helena, Montana, e-mail craig.ravesloot@mso.umt.edu
\end{abstract}

Running Head: CIL services and community participation 


\begin{abstract}
Community living of people with disabilities spans independent living and community engagement. Consumer choice and control of their level of community participation requires community accessibility, resources and supports. Some people with disabilities have difficulties procuring and maintaining these resources. Centers for Independent Living (CIL) are advocacy and service agencies that have been empowering consumers to meet their needs for over 40 years. Despite this history, little is known about the value of CIL services for increasing community participation of people with disabilities. We administered the CIL Participation Service Survey to 420 CIL staff members and 107 CIL board members to examine their opinions about the relative value of different CIL services for increasing community participation of their consumers. Results indicated that both staff and board members have very high regard for the value and quality of CIL services. The IL philosophy of consumer choice and control was among the most highly rated aspects of CIL service delivery for both staff and board members. Overall, staff and board member responses were very consistent in terms of the top rated strengths and weaknesses of CIL services for increasing participation among consumers. Differences appeared to reflect the daily staff focus on specific consumer need versus board members view of larger community issues.
\end{abstract}


Living and participating in one's community of choice is central to freedom of selfdetermination. Unfortunately, for Americans with disabilities, environmental or attitudinal barriers severely limit opportunities for community participation. Specifically, independence for people with disabilities is limited by factors such as inaccessible housing (Maisel, 2006), insufficiency of accessible transportation (Seekins, Enders, Pepper, \& Sticka, 2007), architectural inaccessibility (Gray, Gould, \& Bickenbach, 2003), financial limitations (Carpenter, Forwell, Jongbloed, \& Backman, 2007), and social discrimination (McClain, Medrano, Marcum, \& Schukar, 2000). Centers for Independent Living (CILs), first established as grass roots organizations that were later funded by the US Government, help to solve community living problems for people with disabilities (Dejong, 1979).

CILs are non-profit, community-based organizations with a primary mission of empowering individuals with disabilities through advocacy and services that reflect the Independent Living Philosophy, which asserts that consumers should have choice and control over both what services they receive and how they receive them. Title VII of the Rehabilitation Act of 1978 provides federal funding for CILs and the Rehabilitation Services Administration (RSA) of the U.S. Department of Education oversees CIL services.

The four core services provided by CILs include peer counseling, information and referral, independent skills training, and advocacy. The first core service, peer counseling, encourages individuals to collaborate with other people with disabilities who are independent and active members of the communities. The second, information and referral, involves providing up-to-date information about resources available in the community that promote independent living (e.g., accessible transportation services). The third, independent skills training, provides education about skills necessary for independent living like self-management 
of health conditions. The fourth, advocacy, falls into two categories: individual advocacy and systems advocacy. Individual advocacy involves helping individuals learn to request and negotiate for the IL services they need. Systems advocacy, on the other hand, involves catalyzing community and systems change that maximize availability of IL services (e.g., personal assistant services) and community accessibility (e.g., use of universal design principles in construction). While these core services are mandated in the federal legislation that funds the majority of CILs, the service constellation is less definitional than the IL philosophy of service delivery.

When CILs provide services consistent with independent living philosophy, they foster empowerment by encouraging consumers to make their own choices and control the services they elect. From this perspective, CIL staff teach individuals to meet their own needs, rather than meeting those needs on their behalf. For example, rather than finding people accessible homes, CIL staff might teach someone how to advocate for fair housing rights and help them compile a list of contact resources. By working with people with disabilities instead of for people with disabilities, CILs preserve their commitment to consumer choice and control (Darrah, MagilEvans, \& Adkins, 2002).

Similar to other non-profit human service agencies, CILs are typically organized with an executive director who is responsible for direct service staff and who answers to a board of directors. The 1992 Amendments of the Rehabilitation Act require that the majority of CIL board members and staff have disabilities themselves. This addendum reflects the philosophy that no one knows better about the service needs and service delivery approaches that promote independent living than people with disabilities themselves, and is believed to be fundamental to the maintenance of IL philosophy within the organization (Roberts, 1977). 
Ultimately, the responsibilities of board members are not dependent upon obligations to the CIL, but instead upon obligations to the community, which is served by the CIL. In fact, board members are held accountable under criminal and civil law to develop a resourceful organization that is successful in meeting the needs of the community (Batavia, 1989). When overseeing operations of the CIL, board members must establish goals that are appropriate, realistic, and quantifiable. Additionally, board members should exercise caution in maintaining operations that are uninfluenced by external organizations, such as corporate sponsors or private foundations. Instead, board members must remain vigilant in maintaining operations that are guided by concrete goals to address needs within the community.

To summarize, CILs provide community services according to a philosophy of consumer choice and control that are overseen by a board of directors that works on behalf of all people with disabilities in the community. Unfortunately, little is known about the effectiveness of these services for the intended outcomes. We conducted this study to examine the perspectives of CIL staff and board members on the value of CIL services for improving the community participation of the people they serve. We reasoned that staff and board members might have divergent opinions about services and further, the board members may be more critical of service effectiveness than those providing the service. We used a participatory action research design to explore similarities and differences between staff and board members about their opinions regarding the effectiveness of CILs services for improving community participation of the consumers they serve.

\section{Method}

\section{Participants}


We randomly selected 90 CILs from non-overlapping membership records provided by the National Council on Independent Living (NCIL) and the Association of Programs for Rural Independent Living (APRIL) and solicited their participation in a mail-based survey. For staff, we received useable returns from 420 CIL staff who represented 61 CILs $(67.8 \%$ center response rate). For board members, we received 107 surveys from 42 CILs $47 \%$ center response rate). While $90 \%$ of the centers (55) had three or more staff return a survey, only $38.1 \%$ of the centers had three or more board members respond.

The centers were established on average 20.3 years ago $(\mathrm{sd}=8.28)$ and they employed an average of 26.9 staff $(\mathrm{sd}=24.3)$. These staff had worked at the CIL for an average of 5.6 years $(\mathrm{sd}=5.1)$ and $67.4 \%$ reported some type of disability. Table 1 lists the primary impairment type

of staff respondents. Respondents also represented a range of positions within the CIL including, 95 independent living skills trainers (24.3\%), 81 consumer advocates (20.8\%), 73 information and referral specialists, (18.7\%) 42 peer councilor's (10.8\%), 37 directors $(9.5 \%)$ and 20 Americans with Disabilities (ADA) compliance specialists (4.8\%).

\section{Measures}

We developed the CIL Participation Services Survey (CILPSS) to measure respondents' values and judgments regarding their center's services that included respondent demographic and CIL characteristic questions. Briefly, we used a participatory action research (PAR) approach to identify themes and items for the survey that was based on the Concerns Report Method (CRM) (Fawcett, de Balcazar, Johnson, et al., 2000). First, we engaged CIL staff members to identify services that they judged are related to improving community participation of their consumers and cross-validated those services with a review of $100 \mathrm{CIL}$ websites and content from the International Classification of Function, Disability and Health (WHO, 2001). These services 
were listed in a survey and then broadly distributed to a new sample that evaluated each service on two dimensions: (1) their estimate of the importance of the service for increasing community participation and, (2) their satisfaction with how well their own center provides the service. Both importance and satisfaction were rated using a 4-point scale anchored by "not important" or "very dissatisfied" on one end and "very important" or "very satisfied" on the other.

Respondents could check "N/A" for items that were "Not Applicable" to the services provided by their CIL, for instance, when their center did not provide a particular service. Community participation was defined for respondents as "employment, volunteer activities as well as recreation and educational activities."

The survey included 81 items used to measure 12 service content domains and a service delivery process dimension. The process dimension was developed to assess how services were provided. The service content domains included: advocacy, housing, independent living skills, information/referral, peer support, transportation, employment, recreation, assistive technology, mental health, health care and nursing home emancipation. These domains were assessed with between 2 and 14 items for each (e.g., nursing home emancipation had 2 items while the process dimension had 14). The score for each service is a combination of relative importance and relative satisfaction such that each issue falls into one of three categories: (1) a non-important issue, (2) an issue of high importance and high satisfaction, defined as a strength, or (3) an issue of high importance and low satisfaction, defined as a weakness.

In addition to CIL service items, the measure included basic information about each center including the age of the center, number of staff, annual budget, number of collaborators, number of years the staff had worked at the center, impairment status of the respondent, position 
held in the center, geographic service area (i.e., metropolitan, non-metropolitan or rural) and the services provided by the CIL. Finally, all items were formatted for forms that could be scanned.

\section{Analysis}

All surveys were scanned using a scantron machine and data was visually checked for scanning errors. All data were imported into the Statistical Package for the Social Sciences (SPSS) version 16. Item characteristics were examined with descriptive statistics. Consistent with the CRM, we computed strength and weakness scores for each item. Strengths were calculated as the product of importance rating by satisfaction rating indicating those items were rated as most important and have the highest satisfaction. Weakness was computed as the product of importance ratings and the inverse of satisfaction ratings, indicating that those items were rated as having the highest levels of importance, but the lowest levels of satisfaction. Descriptive statistics were computed for the average importance, strengths and weaknesses for staff members and board members separately. Comparisons between staff and board members were made with independent samples t-tests using the item raw scores.

Results are expressed in terms of the average percentage for each item defined by the sum of all responses divided by the total possible score had all respondents rated each item at its highest value. Because the service delivery process is fundamental to the services CILs provide, we analyzed the content and process dimensions together in order to explore the veracity of IL philosophy within the context of services delivered and to explore the relative value staff and board members accorded IL philosophy for increasing community participation.

\section{Results}

Results from the survey reflect the opinions of CIL staff and board members about the relative value of their center's services for increasing consumer community participation. They 
also show the relative strengths and weaknesses defined by ratings of importance and satisfaction for each service type or process. Overall, CIL staff and board members rated both the importance and their satisfaction with services very highly with overall average raw score importance ratings across all items equal to 2.63 and satisfaction equal to 2.30 (possible range $=$ $0-3)$.

The top 10 items rated for their importance by staff and board members are included in Table 2. Staff and board members shared seven of the top ten services. There was only one statistically significant difference in the ratings between staff and board members with staff rating "Provides services in a way that empowers consumers to make their own choices" as more important than board members.

The top 10 strengths as indicated by the product of importance and satisfaction ratings are included in Table 3. Staff and board members shared 8 of 10 services indicating substantial agreement on which services represent strengths for CILs. There were two statistically significant differences in strengths scores between these groups. First, staff scores for "Makes referrals to other disability support service providers (e.g., Veterans Administration, Bureau of Indian Affairs, Paralyzed Veterans of America)" were higher than board members. Second, board member scores for “Increases the community's sensitivity concerning attitudes about people with disabilities" were higher than staff.

The top 10 weaknesses as indicated by the product of the importance ratings by the inverse of satisfaction ratings are included in Table 4. Staff and board members shared 5 of the top 10 services when scored for weaknesses of the CIL suggesting more disparate views than was observed for the CIL service importance or strengths. Further, statistically significant differences in ratings between staff and board members were observed on five items. Staff 
member scores for "Works with places of worship and their programs so that people with disabilities can participate to the extent they choose," "Provides education and computer skills workshops," "Helps consumers maintain good health by providing health promotion services (e.g., Living Well with a Disability, exercise program)" and "Provides mental health counseling services" were ranked higher than board members, indicating staff viewed them as more important weaknesses. In contrast, board member scores for "Maintains a registry of accessible housing" were greater indicating board members viewed it as a more important weakness than staff.

\section{Discussion}

Centers for Independent Living are premier community-based, non-profit, service and advocacy organizations charged with improving the community living and participation of people with disabilities. CILs approach this task with many tools that reflect the diversity of people and places in the communities they serve. We found evidence that staff and board members view CIL services very favorably and with remarkable consistency both to the tenets of IL philosophy and with each other.

Overall, both CIL staff and board members view CIL services as enormously effective for improving community participation of people with disabilities. Their ratings across 75 service content related questions and 14 process dimensions highlight the importance of facilitating consumer choice and developing self-advocacy skills as the most important features of increasing consumer participation. Ed Roberts, sometimes referred to as the "father" of independent living, first described these tenets of independent living. These results suggest the philosophy of IL is alive and well in the ideology of CIL staff and board members. Other 
services deemed important for increasing participation were helping consumers find benefits and personal assistance services.

Services are only one aspect of IL, however. Advocacy and systems change were rated as equal, if not more important by many respondents. These results reflect the importance of systems change and accessibility, working with community partners, and influencing community attitudes toward people with disabilities.

Interestingly, differences between staff and board importance ratings appear to reflect this tension between service delivery and systems advocacy, with staff ratings leaning more toward services and board members having a greater preference toward advocacy. For example, the highest rated transportation item rated by board members involved advocating for accessible transportation systems, while staff rated making referrals for accessible transportation services as the most important transportation item. These differences seem to appropriately reflect the staff attention to the needs of those they serve while board members responded in terms of the larger community context.

Staff and board members had similar views of CIL strengths. The similarity between the top strengths and those with the greatest importance reflect that both staff and board members are very satisfied with the services they deem are most important to increasing participation among consumers. It is noteworthy that the hallmarks of CIL service delivery are not only valued, but the quality of those services are very highly viewed by both those providing them and by those with policy making roles. These results appear to support the core mission of IL both ideologically and in practice.

The two differences between board member and staff strength scores are instructive for each group. First, staff may be doing a better job making referrals to other disability support 
providers than is recognized by board members. Second, the work of CIL staff may be having a greater impact on the community's sensitivity to disability than is recognized by staff members. As with importance ratings, the day-to-day focus of staff to help individuals probably gives them a better view of how referrals are made while the contextual view of board members may allow them to see the broader impact of CIL services.

Comparing staff and board weakness scores seems to reflect the same effect noted above. Again, each perspective is important and needs to be recognized by both groups. First, in their daily contact with consumers, staff noted weaknesses in the CIL's ability to address the health and mental health issues that impact their work with consumers. Additionally, they see consumers' participation challenged by lack of computer skills, access to worship facilities, opportunities for employment and housing accessibility and they rated their satisfaction with providing services to address these issues somewhat lower than other services. In contrast to the staff, issues around housing and employment were of greater concern to board members. Again, board members concerns seemed to revolve around systems change while CIL personnel seek opportunities to affect change through service provision.

Another important result of this survey was the highly rate item "Uses partnerships with other agencies in the community to help consumers meet IL needs (e.g., transportation providers, housing authority)," which was rated in the top 10 for importance and strengths by CIL staff and board members. This highlights another very important process dimension of CIL service delivery. CILs that use partnerships may be better positioned to help participants not only solve IL problems, but also increases exposure of their clients to other community members and resources. While the effect of this is unknown, we may speculate that this strategy both translates into increased community participation for consumers and positively effects the 
efficiency and reach of CIL services. Finally, this strategy may facilitate other valued CIL processes including improving community accessibility and attitudes toward people with disability as CIL staff educate community partners about IL philosophy.

\section{Limitations}

The study has a number of weaknesses worth noting. First, the CRM is self-report and is subject to all of the short-comings commonly associated with asking stakeholders about their experiences. For the CILPSS, these limitations may have systematically biased responses; however, the effect of this bias on results is unknown. We conceptualized the CILPSS as an opinion survey to understand how staff and board members view their CIL services. Within that frame, systematic bias would simply be an endogenous element of the opinions themselves. To truly estimate the value and quality of services, one would need an objective measure of services. Our purpose for this study was different. Another weakness is the potential for sampling bias due to self-selection of participants into the study, despite our efforts to randomly sample programs and achieve very good response rate from them. If the CILs that did not respond were predominantly seen as weak by the CIL staff and board members, the results presented here would overestimate the positivity of staff and board members toward CIL services.

\section{Future Directions}

These results suggest future research to further understand the role of CIL services for increasing the community participation of people with disabilities. First, it would be useful to examine consumer level outcomes using one of the participation measures (e.g., Gray, Hollingsworth, Stark \& Morgan, 2006) to detect differences in outcomes based on service delivery. With the overall effect size known, it would be useful to conduct service component analysis in prospective studies to examine alternative service delivery strategies for their effect 
on community participation. For example, do CIL programs that use multiple community partnerships to help consumer's meet their needs have any impact on the community participation of consumers.

In addition to research directions, the CILPSS may be a valuable tool for state independent living councils, board of directors and executive directors who are interested in learning about the opinions staff and board members have about the CIL services provided. Results from surveys collected for a specific center could be compared to the results presented here to examine how well staff opinions reflect opinions of this nationally representative sample. Or, results could be used to examine how well the IL philosophy or other key IL component is represented in the staff and board member opinions. Alternatively, the CILPSS could help centers or states identify weaknesses the CIL staff observe to guide development of new programs or services. When new programs are implemented, results could identify staff and board member opinions about the effect of these initiatives on the community participation of the CIL consumers (e.g., implementation of a new employment, transportation or housing initiative). This kind of information could help direct programming as well as staff and board member training in support of that programming.

\section{Conclusion}

Centers for Independent Living have a long history of empowering consumers to meet their own needs and motivating communities to create accessible places that include people with disabilities. We created the Center for Independent Living Participation Services Survey to examine staff and board member opinions about those services deemed most useful for increasing the community participation of their consumers. Results indicated that both staff and consumers have a high regard for the services they provide. Even more importantly, results demonstrate that the IL philosophy for consumer choice and control is evident in both staff and 
board members suggesting the great success IL programs have had in establishing their core philosophy to those directing and those providing IL services. 


\section{References}

Batavia, A. I. (1989). The Legal Liability of Independent Living Centers. Houston, TX: ILRU Research and Training Center on Independent Living at TIRR.

Carpenter, C., Forwell, S.J., Jongbloed, L.E., \& Backman, C.L. (2007). Community participation after spinal cord injury. Archives of Physical Medicine and Rehabilitation, $88(4), 427-433$.

Darrah, J., Magil-Evans, J., \& Adkins, R. (2002). How well are we doing? Families of adolescents or young adults with cerebral palsy share their perceptions of service delivery. Disability and Rehabilitation, 24(10), 542-549.

DeJong, G. (1979). Independent living: From social movement to analytic paradigm. Archives of Physical Medicine and Rehabilitation, 60, 435-446.

Fawcett, S. B., Suarez de Balcazar, Y., Johnson, M. D., Whang-Ramos, P., Seekins, T., \& Bradford, B. (2000). Handbook of the disabled citizens' concerns report method. The Research and Training Center on Independent Living, The University of Kansas.

Gray, D.B., Gould, M., \& Bickenbach, J.E. (2003). Environmental barriers and disability. Journal of Architectural and Planning Research, 20(1), 29-37.

Gray DB, Hollingsworth HH, Stark SL, Morgan Ka. (2006). Participation survey/mobility: Psychometric properties of a measure of participation for people with mobility impairments and limitations. Archives of Physical Medicine and Rehabilitation, 87: 189197.

Maisel, J.L. (2006). Toward inclusive housing and neighborhood design: A look at visitability. Community Development, 37(3), 26-34. 
McClain, L., Medrano, D., Marcum, M., \& Schukar, J. (2000). A qualitative assessment of wheelchair users' experience with ADA compliance, physical barriers, and secondary health conditions. Topics in Spinal Cord Injury Rehabilitation, 6(1), 99118.

Roberts, E.V. (1977). Foreword. In Pflueger, S.S. Independent Living (pp. ii-iv). Washington, DC: Institute for Research Utilization.

Seekins, T., Enders, A., Pepper, A., \& Sticka, S. (2007). Allocation and use of Section 5310 funds in urban and rural America. Journal of Public Transportation, 10(1), 81-101.

World Health Organization. (2001). International classification of functioning, disability and health. 2001. Geneva: WHO. 
Table 1: Impairment type reported by staff respondents

\begin{tabular}{lcc} 
Impairment Type & N & Percent \\
\hline Physical & 146 & 36.9 \\
Psychiatric & 57 & 14.4 \\
Hearing & 35 & 8.8 \\
Learning & 33 & 8.3 \\
Visual & 33 & 8.3 \\
Other & 61 & 15.4 \\
None & 129 & 32.6 \\
\hline
\end{tabular}


Table 2: Top 10 item importance ratings for both CIL staff and board members

\begin{tabular}{|c|c|c|c|c|}
\hline \multirow[t]{2}{*}{ Item } & \multicolumn{2}{|c|}{ Staff } & \multicolumn{2}{|c|}{ Board } \\
\hline & Rank & $\%$ & Rank & $\%$ \\
\hline $\begin{array}{l}\text { Provides services in a way that empowers consumers to } \\
\text { make their own choices. }\end{array}$ & 1 & 97.4 & 7 & $94.0^{*}$ \\
\hline $\begin{array}{l}\text { Advises consumers about benefits they are eligible for (e.g., } \\
\text { Medicaid, SS, housing). }\end{array}$ & 2 & 97.0 & 5 & 94.6 \\
\hline $\begin{array}{l}\text { Provides services in a way that encourages consumers to } \\
\text { advocate for their own rights. }\end{array}$ & 3 & 96.9 & 2 & 95.9 \\
\hline $\begin{array}{l}\text { Works for the rights of people with all types of } \\
\text { disabilities/chronic health concerns (e.g., sensory, mental } \\
\text { health). }\end{array}$ & 4 & 96.8 & 1 & 96.9 \\
\hline $\begin{array}{l}\text { Uses partnerships with other agencies in the community to } \\
\text { help consumers meet IL needs (e.g., transportation providers, } \\
\text { housing authority). }\end{array}$ & 5 & 95.7 & 9 & 93.2 \\
\hline $\begin{array}{l}\text { Provides services to help integrate consumers into the } \\
\text { community once emancipated from nursing homes (e.g. peer } \\
\text { support, IL skills training). }\end{array}$ & 6 & 94.8 & 11 & 93.0 \\
\hline $\begin{array}{l}\text { Helps people with disabilities find the types and amounts of } \\
\text { personal assistance service they need. }\end{array}$ & 7 & 94.7 & 4 & 94.7 \\
\hline $\begin{array}{l}\text { Is sensitive to the readiness and confidence level of new } \\
\text { consumers when planning services. }\end{array}$ & 8 & 94.6 & 17 & 91.8 \\
\hline $\begin{array}{l}\text { Increases the community's sensitivity concerning attitudes } \\
\text { about people with disabilities. }\end{array}$ & 9 & 94.5 & 3 & 95.6 \\
\hline $\begin{array}{l}\text { Encourages community partners to provide services that are } \\
\text { consistent with IL philosophy (e.g., consumer choice and } \\
\text { empowerment). }\end{array}$ & 10 & 94.4 & 12 & 92.6 \\
\hline $\begin{array}{l}\text { Serves consumers of diverse racial/ethnic background in a } \\
\text { culturally competent manner. }\end{array}$ & 18 & 92.9 & 6 & 94.1 \\
\hline $\begin{array}{l}\text { Is involved in grassroots system advocacy to make } \\
\text { community infrastructure more accessible (e.g., public } \\
\text { transportation, housing, education). }\end{array}$ & 17 & 93.2 & 8 & 93.5 \\
\hline $\begin{array}{l}\text { Helps the community develop and maintain affordable, } \\
\text { accessible transportation that meets consumer need. }\end{array}$ & 22 & 92.2 & 10 & 93.2 \\
\hline
\end{tabular}

Note: Percent is the percentage of possible score across all respondents. *Denotes statistically significant difference $(\mathrm{p}<.05)$. 
Table 3: Top 10 item strength scores for both CIL staff and board members

\begin{tabular}{|c|c|c|c|c|}
\hline \multirow[t]{2}{*}{ Item } & \multicolumn{2}{|c|}{ Staff } & \multicolumn{2}{|c|}{ Board } \\
\hline & Rank & Score & Rank & Score \\
\hline $\begin{array}{l}\text { Advises consumers about benefits they are eligible for (e.g., } \\
\text { Medicaid, SS, housing). }\end{array}$ & 1 & 90.7 & 1 & 89.2 \\
\hline $\begin{array}{l}\text { Provides services in a way that empowers consumers to make } \\
\text { their own choices. }\end{array}$ & 2 & 87.2 & 3 & 86.4 \\
\hline $\begin{array}{l}\text { Provides services in a way that encourages consumers to advocate } \\
\text { for their own rights. }\end{array}$ & 3 & 86.0 & 2 & 87.1 \\
\hline $\begin{array}{l}\text { Makes referrals to other disability support service providers (e.g., } \\
\text { Veterans Administration, Bureau of Indian Affairs, Paralyzed } \\
\text { Veterans of America). }\end{array}$ & 4 & 85.3 & 23 & $76.4^{*}$ \\
\hline $\begin{array}{l}\text { Uses partnerships with other agencies in the community to help } \\
\text { consumers meet IL needs (e.g., transportation providers, housing } \\
\text { authority). }\end{array}$ & 5 & 85.0 & 6 & 82.2 \\
\hline Makes referrals to accessible transportation / resources. & 6 & 84.4 & 11 & 80.6 \\
\hline $\begin{array}{l}\text { Helps people with disabilities find the types and amounts of } \\
\text { personal assistance service they need. }\end{array}$ & 7 & 83.7 & 5 & 83.1 \\
\hline $\begin{array}{l}\text { Uses traditional telecommunications to provide services (e.g., } \\
\text { telephone, email). }\end{array}$ & 8 & 83.6 & 9 & 81.2 \\
\hline $\begin{array}{l}\text { Works for the rights of people with all types of } \\
\text { disabilities/chronic health concerns (e.g., sensory, mental health). }\end{array}$ & 9 & 82.9 & 4 & 84.0 \\
\hline $\begin{array}{l}\text { Is sensitive to the readiness and confidence level of new } \\
\text { consumers when planning services. }\end{array}$ & 10 & 81.4 & 8 & 81.2 \\
\hline $\begin{array}{l}\text { Serves consumers of diverse racial/ethnic background in a } \\
\text { culturally competent manner. }\end{array}$ & 13 & 79.3 & 7 & 81.8 \\
\hline $\begin{array}{l}\text { Increases the community's sensitivity concerning attitudes about } \\
\text { people with disabilities. }\end{array}$ & 27 & 74.5 & 10 & $80.6^{*}$ \\
\hline
\end{tabular}

Note: Score is the importance rating times the satisfaction rating. *Denotes statistically significant difference $(\mathrm{p}<.05)$. 
Table 4: Top 10 item weakness scores for both CIL staff and board members

\begin{tabular}{|c|c|c|c|c|}
\hline \multirow[t]{2}{*}{ Item } & \multicolumn{2}{|c|}{ Staff } & \multicolumn{2}{|c|}{ Board } \\
\hline & Rank & Score & Rank & Score \\
\hline $\begin{array}{l}\text { Works with places of worship and their programs so that people } \\
\text { with disabilities can participate to the extent they choose. }\end{array}$ & 1 & 29.06 & 7 & $22.1 *$ \\
\hline $\begin{array}{l}\text { Provides information about accessible medical services (e.g., } \\
\text { providers with accessible exam tables). }\end{array}$ & 2 & 26.8 & 2 & 23.1 \\
\hline Provides education and computer skills workshops. & 3 & 26.5 & 17 & $20.2 *$ \\
\hline $\begin{array}{l}\text { Provides information about accessible community resources in } \\
\text { the Center's newsletter and on the website (e.g., recreation, } \\
\text { restaurants, travel, etc.). }\end{array}$ & 4 & 26.0 & 8 & 22.1 \\
\hline Works to increase accessibility of medical facilities and services. & 5 & 25.8 & 16 & 20.3 \\
\hline $\begin{array}{l}\text { Helps consumers maintain good health by providing health } \\
\text { promotion services (e.g., Living Well with a Disability, exercise } \\
\text { program). }\end{array}$ & 6 & 24.2 & 22 & $18.8 *$ \\
\hline $\begin{array}{l}\text { Uses emerging telecommunications to provide services (e.g., } \\
\text { podcasts, blogs, text messaging, video phone). }\end{array}$ & 7 & 24.1 & 6 & 22.2 \\
\hline $\begin{array}{l}\text { Works with employers to assure people with disabilities have the } \\
\text { same chances for advancement and promotion. }\end{array}$ & 8 & 23.9 & 11 & 21.3 \\
\hline Provides mental health counseling services. & 9 & 23.6 & 47 & $15.6^{*}$ \\
\hline $\begin{array}{l}\text { Works with housing authority to make sure accessible housing is } \\
\text { available. }\end{array}$ & 10 & 23.4 & 3 & 22.7 \\
\hline Maintains a registry of accessible housing & 54 & 16.7 & 1 & $24.7 *$ \\
\hline Provides money management training to consumers. & 25 & 20.9 & 4 & 22.5 \\
\hline $\begin{array}{l}\text { Provides the services and supports people need to obtain and } \\
\text { succeed in employment. }\end{array}$ & 19 & 21.3 & 5 & 22.3 \\
\hline $\begin{array}{l}\text { Furthers employment opportunities for consumers using } \\
\text { community partnerships (e.g., one stop, business owners). }\end{array}$ & 11 & 23.3 & 9 & 21.4 \\
\hline $\begin{array}{l}\text { Provides vocational preparation services (e.g., job coaches, } \\
\text { interview skills, etc.). }\end{array}$ & 15 & 21.9 & 10 & 21.3 \\
\hline
\end{tabular}

Note: Score is the importance rating times the inverse of the satisfaction rating. Higher scores reflect greater weakness. *Statistically significant difference $(\mathrm{p}<.05)$. 